\title{
Can Health 2.0 Address Critical Healthcare Challenges? Insights from the Case of How Online Social Networks Can Assist in Combatting the Obesity Epidemic
}

\author{
Janine Hacker \\ Universität Erlangen-Nürnberg \\ janine.hacker@fau.de
}

\author{
Nilmini Wickramasinghe \\ Epworth HealthCare \& Deakin University
}

\section{Carolin Durst}

Universität Erlangen-Nürnberg

\section{Abstract}

One of the serious concerns in healthcare in this 21st century is obesity. While the causes of obesity are multifaceted, social networks have been identified as one of the most important dimensions of people's social environment that may influence the adoption of many behaviours, including health-promoting behaviours.

In this article, we examine the possibility of harnessing the appeal of online social networks to address the obesity epidemic currently plaguing society. Specifically, a design science research methodology is adopted to design, implement and test the Health 2.0 application called "Calorie Cruncher". The application is designed specifically to explore the influence of online social networks on individual's health-related behaviour. In this regard, pilot data collected based on qualitative interviews indicate that online social networks may influence healthrelated behaviours in several ways. Firstly, they can influence people's norms and value system that have an impact on their health-related behaviours. Secondly, social control and pressure of social connections may also shape health-related behaviours, and operate implicitly when people make food selection decisions. Thirdly, social relationships may provide emotional support.

Our study has implications for research and practice. From a theoretical perspective, the article inductively identifies three factors that influence specific types of health outcomes in the context of obesity. From a practical perspective, the study underscores the benefits of adopting a design science methodology to design and implement a technology solution for a healthcare issue as well as the key role for online social media to assist with health and wellness management and maintenance.

Keywords: Online Social Networks; Health 2.o Application; Design Science Methodology; Obesity.

\section{Introduction}

A central aspect of participatory medicine is an empowered patient who understands critical issues of their underlying health issue (Lejbkowicz, Caspi, \& Miller, 2012). The following examines critical issues concerning patient empowerment in the context of obesity. The article proffers a technology solution to enable both heightened patient empowerment and understanding by the patient of the key dynamics in this context.

One of the serious concerns in healthcare in this 21st century is obesity (WHO, 2000). Today, there exists more than one billion overweight adults out of which at least 300 million are medically obese (WHO, 2011b). Not only is obesity itself problematic but it also leads to various secondary disorders such as diabetes, heart diseases and cancer, (WHO, 2011b), which in turn adds burdens to the challenged healthcare delivery systems, especially in terms of costs caused by obesity and the likelihood of recovery (Wickramasinghe, Bali, Goldberg, \& Troshani, 2012). 
The change of an individual's behaviour is the key to successful primary prevention of obesity. Traditional measures are established by human-to-human communication (e.g., group therapies, counselling sessions) or mediated-communication (e.g., media campaigns). A wellestablished human-to-human measure is personal fitness coaching. But as new technologies are arising, there are new possibilities through web, mobile, and other ambient technologies to establish human-computer interaction (HCI) to foster a healthier lifestyle (Oinas-Kukkonen \& Harjumaa, 2009).

Mobile devices, like smartphones, facilitate an easy and fast way to communicate (Oulasvirta, Rattenbury, Ma, \& Raita, 2012) by creating, accessing, and sharing information (OinasKukkonen, 2010). In the healthcare context, such services can connect individuals with similar interests, for example, via online communities. Providing social support (Hwang et al., 2010) and informational support, online health communities allow people to seek information, communicate with others with the same or similar diseases, share health guidance, and compare treatment and medication strategies. The ubiquitous accessibility at any time, the anonymity of the medium, as well as the access to greater expertise are regarded as the main benefits of online health communities (Maloney-Krichmar \& Preece, 2002).

Interestingly, social networks have also been identified as one of the most important dimensions of people's social environment that may influence the adoption of many behaviours, including health-promoting behaviours (McNeill, Kreuter, \& Subramanian, 2006). Previous studies have focused on the spread of obesity within traditional (offline) social networks (Christakis \& Fowler, 2007; Fowler \& Christakis, 2008). As ideas, behaviours and trends are passed on within people's social environment, a person-to-person spread of obesity within social networks has been suggested (Christakis \& Fowler, 2007). Lately, the dramatic growth of electronic (online) social networks has resulted in a blurring of the boundaries between the real and the virtual world (BVDW, 2010). Online social networks have become part of many people's everyday life and are - just as "real world contacts" - suggested to influence the diffusion and adoption of health-related behaviours (Ma, Chen, \& Xiao, 2010).

It is the ultimate goal of this research to address obesity by reinforcing positive health-related behaviours with innovative Health 2.0 solutions. Such interventions require a better understanding of the relationship between an individual's online social network and their health-related behaviours. Building upon our prior work on this topic (Durst, Viol, \& Wickramasinghe, 2013; Wickramasinghe, Teoh, Durst, \& Viol, 2013), this article explores the relationship between online social networks, health-related behaviours, and an individual's body weight based on qualitative interviews. Embedded within a design science methodology, the interviews are used to derive design implications for developing a Health 2.0 Facebook application, which collects data in order to investigate the aforementioned relationship. Moreover, the interviews enable us to extend our previously developed conceptual model (Durst et al., 2013).

The remainder of this article is organised as follows. After elaborating on obesity, social networks, and health, we review current work regarding obesity in the context of Health 2.0. We then present our conceptual model and develop a Health 2.o Facebook application using design science research methodology. Finally, we discuss our findings and the limitations of the study.

\section{Background}

\subsection{Classification}

The most common measure to classify underweight, overweight and obesity in adults is the Body-Mass-Index (BMI), developed by the Belgian Mathematician Adolphe Quetelet in 1871 (Quetelet, 1871). The BMI is defined as an individual's body weight in kilograms divided by the square of his or her height in meters $\left(\mathrm{kg} / \mathrm{m}^{2}\right)$ : 


$$
B M I=\frac{\operatorname{mass}(\mathrm{kg})}{(\text { height }(\mathrm{m}))^{2}}
$$

A person with a BMI of less than 18.5 is considered underweight (WHO, 2011b). A BMI greater than 25 is regarded as overweight and above 30 is regarded as obese (WHO, 2011a).

\subsection{Causes of overweight and obesity}

The causes of overweight and obesity are multifaceted and result from the co-occurrence and interaction of several factors (WHO, 2000, 2011a, 2011b). Individual medical conditions may lead to obesity; yet, the dramatic increase in obese people worldwide cannot be explained by medical conditions alone (WHO, 2000). The WHO identifies an energy imbalance between consumed and expended calories as the fundamental cause of obesity (WHO, 2011a, 2011b). This energy imbalance is determined by individual behaviours and lifestyle choices, such as dietary and physical activity patterns (Huffman, 2011; WHO, 2011a, 2011b). In turn, individual behaviours and lifestyle choices are shaped by people's social and economic environment. Thus, in this study we focus on social factors influencing an individual's propensity to engage in a healthy lifestyle.

\subsection{Social networks, social capital, and health}

McNeill et al identify social networks as one of the most important dimension of people's social environment to influence the adoption of health-promoting behaviours (McNeill et al., 2006). As such, social networks consist of a finite set of actors or people and the relationships between them (Wasserman \& Faust, 1994).

Drawing on their social networks, people have access to different kinds of resources forming their social capital. Social capital theory is rooted in the social sciences (Hyyppä, 2010) and has been used to explain a wide range of societal phenomena. For instance, Marmot \& Wilkinson (2005) study social capital as a determinant of public health in medical sociology. While different notions of social capital exist (cf. Rostila, 2011), this study is grounded in the networkbased notion of social capital. Thus, social capital is defined as the resources that are embedded in one's social network and that can be accessed or mobilised through relationships in the network (Lin, 2001, p29). Commonly, these relationships are categorised into strong and weak ties. Strong ties are intimate bonds between family members or close friends that are maintained regularly and permanently (Granovetter, 1973). Tending to be concentrated in particular groups, strong ties are of informal nature and occur between network members with a shared social identity (ibid). Strong ties can be related to bonding social capital (Putnam, Leonardi \& Nanetti, 1994). In contrast, weak ties emerge as non-intimate bonds between acquaintances (Granovetter, 1973). Maintained infrequently and inconsistently, weak ties may be formal contacts and are more likely to link members of different small groups (Rostila, 2011). Weak ties tend to generate informational support whereas informal and strong ties are associated with the provision of emotional support (ibid). Weak ties overlap with the idea of bridging social capital (Putnam et al., 1994).

Regarding epidemic diseases in social networks, Gershenson (2011) distinguishes between communicable diseases transmitted through e.g. bacteria and viruses, such as influenza and HIV, and non-communicable diseases, e.g. cancer and diabetes, that can - by definition - not be transmitted (Gershenson, 2011). However, he acknowledges, the spread of ideas and behaviours as well as contagious trends and habits provides a powerful substitute for physical mechanisms to spread diseases and leads to a so-called "social infection" (ibid). Thus, the risk factors for non-communicable diseases are spread across social networks. In the context of this research, the association between social networks, social capital, health-related behaviours and obesity is of particular importance. Having conducted a longitudinal study over 32 years, Christakis and Fowler provide three explanations for the collective dynamics of obesity in a large social network (Christakis \& Fowler, 2007). Further, they argue that the susceptibility of a person to become obese increases when close members in the social network become obese. Thus, the chance of becoming obese is positively correlated with the closeness and strength of 
the relationship. Though the design and findings of their study have been criticised (e.g. in Cohen-Cole \& Fletcher, 2008), a number of papers support their line of argument.

For instance, Madan et al. found that health-related behaviours of peers correlate (Madan, Moturu, Lazer, \& Pentland, 2010). Moreover, a literature review by Hammond (2010) examining the relationship between social influence and obesity points to social influence and social network structures being important factors in obesity. Finally, Moore, Daniel, Gauvin \& Dubé (2009) found a relationship between social capital and likelihood of overweight and obesity.

\subsection{Obesity in the context of Health 2.0}

Social media and Web 2.0 technologies are nowadays applied in various areas. As to healthcare, the use of Web 2.0 technologies in the context of this research is referred to as Health 2.0, which is defined as the "combination of health data and health information with (patient) experience through the use of ICT" (Bos, Marsh, Carroll, Gupta, \& Rees, 2008) or "user generated healthcare" (Bos, Carroll, \& Marsh 2008).

Embracing patient-centred health informatics, Health 2.0 applications may become an effective self-care information and disease self-management tool in the future. For instance, online health communities allow people to seek information, communicate with others with the same or similar problems, to share health guidance and compare treatment and medication strategies. The accessibility from everywhere at any time, anonymity of the medium as well as the access to greater expertise are regarded as the main benefits of online health communities (Maloney-Krichmar \& Preece, 2002). Hwang et al. (2010) found an online weight loss community to be an important source of social support for its members.

A number of social media applications deal with obesity. Dedicated blogs, such as Diet Blog (http://www.diet-blog.com), aggregate diet news and advice and cover topics such as exercise, body image and weight loss success stories. Moreover, health social network sites, e.g. SparkPeople (http://www.sparkpeople.com), enable users to connect with each other, to share information, and to support each other in reaching diet and exercise goals.

Besides Health 2.0 applications on the Internet, mobile healthcare applications implemented for smartphones are increasingly used for health promotion and disease prevention (Durst, Hamper, \& Müller, 2013). These applications educate users in terms of risks of specific behaviours, provide users with feedback through tracking and coaching mechanisms, enable social interaction with other users, and include gamification features to keep up user motivation. A great number of mobile healthcare applications focusing on physical activity use sensor technologies, such as GPS sensors for position localisation and tracking, externally connected heart rate sensors for biofeedback or the built-in accelerometer for counting steps. Nutrition-related applications primarily make use of the camera module for scanning nutritional fact labels. Relatively few Health 2.0 applications include social interaction and gamification features (for a comprehensive overview see Durst, Hamper, \& Müller (2013)). However, the interaction between a user and his/her social network may play a crucial role in shaping health-related behaviours as explained in the following section.

\subsection{Possible role for online social networks}

Online social networks are applications that allow users to build a semi-public or public profile within a bounded system, to create explicit linkages to other users and to communicate by sharing information or sending messages between each other (Arnaboldi, Passarella, Tesconi, \& Gazze, 2011). Organised around people, online social networks are structured as egocentric networks within which the individual is at the centre of their personal network (Kaplan \& Haenlein, 2010). Online social networks exhibit a high similarity to offline social relationships, as they offer similar functionalities as unmediated spaces (Arnaboldi et al., 2011). They display people's (extended) offline social network and are primarily used to maintain and reinforce existing offline relationships (Boyd \& Ellison, 2007). 
As individual behaviours and lifestyle choices are shaped by an individual's social environment (WHO, 2011b), online social relationships might exert similar influences. A conceptual model developed in an earlier step of this research suggests a relationship between people's online social network, social capital, health-related behaviours, and their bodyweight (Durst et al., 2013). The conceptual model is based on social capital theory in general as well as on literature focusing on the relationship between social capital and health and the association between online social networks and social capital. In the course of developing the conceptual model (Durst et al., 2013), we identified two main research gaps.

1. Little is known about the types of relationships that matter for specific types of health outcomes in the context of obesity (Moore, 2010).

2. The lack of longitudinal data, that is the cross-sectional nature of many studies, makes it difficult to establish causality in that it cannot be determined whether social networks are a consequence of good health or vice versa (Hyyppä, 2010; Kim, Subramanian, \& Kawachi, 2008; Moore, 2010).

While social networks and social capital have been identified as important determinants of health outcomes, it is not quite clear how they shape health-related behaviours. Thus, as shown in Figure 1, there may be other factors (situated in the "black box") that influence the relationship between social capital and health-related behaviours.

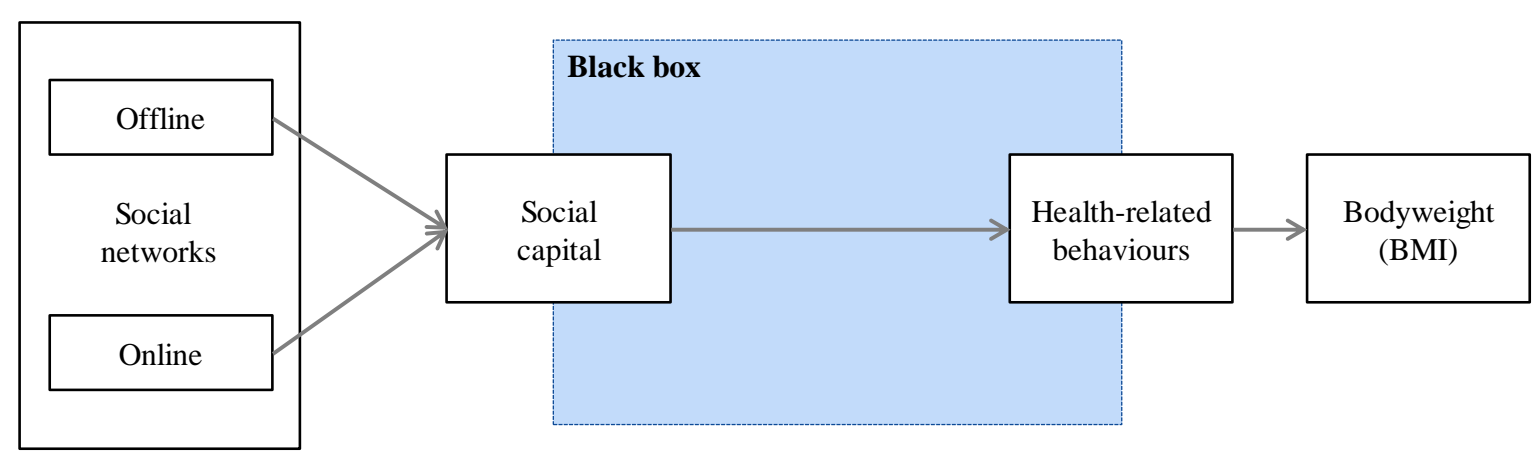

Figure 1. Relationship between social networks, social capital, health-related behaviours and health

Hence, investigating the relationship between social capital and health-related behaviours, including dietary and physical activity patterns and body weight forms the focus of this research. In this article, we report on the design of a Health 2.0 Facebook application developed to support a (future) quantitative study investigating the aforementioned relationship. Preceding this study, explorative interviews with 14 study participants were conducted to gain qualitative insights regarding the relationship between (online) social networks and health-related behaviours. The identified variables help refine the conceptual model and inform the development of features of the Health 2.0 Facebook application.

\section{Design Science Research Methodology}

The design science research methodology (DSRM) process model is one of the most influential design science research methodologies in information System (Peffers, Tuunanen, Rothenberger, \& Chatterjee, 2007). The model is consistent with the principles and guidelines of design science research (Hevner, March, Park, \& Ram, 2004), as explained below. Table 1 shows the application of the DSRM to the Facebook application Calorie Cruncher developed in this paper. 


\begin{tabular}{|l|l|l|}
\hline \multicolumn{1}{|c|}{$\begin{array}{c}\text { DSRM } \\
\text { Activities }\end{array}$} & \multicolumn{1}{|c|}{ Activity description } & \multicolumn{1}{c|}{ Application in this study } \\
\hline $\begin{array}{l}\text { Problem } \\
\text { identification } \\
\text { and motivation }\end{array}$ & $\begin{array}{l}\text { Identify and describe the } \\
\text { importance of the problem }\end{array}$ & $\begin{array}{l}\text { Data collection for the measurement of the } \\
\text { influence of Facebook friends on the individual's } \\
\text { body weight, design implications for the Health } \\
\text { 2.o Facebook application }\end{array}$ \\
\hline $\begin{array}{l}\text { Definition of } \\
\text { objectives for } \\
\text { the application }\end{array}$ & $\begin{array}{l}\text { Define the artefact that } \\
\text { accomplishes the objectives }\end{array}$ & $\begin{array}{l}\text { Design of an application that provides access to } \\
\text { the users' network of Facebook friends and that } \\
\text { gathers data on the users' health-related } \\
\text { behaviours }\end{array}$ \\
\hline $\begin{array}{l}\text { Design and } \\
\text { development }\end{array}$ & $\begin{array}{l}\text { Identify the requirement for } \\
\text { the solution and create the } \\
\text { artefact }\end{array}$ & $\begin{array}{l}\text { Design of the Calorie Cruncher Facebook } \\
\text { application based on 14 qualitative interviews }\end{array}$ \\
\hline Demonstration & Use artefact to solve problem & $\begin{array}{l}\text { Proof of concept of the Calorie Cruncher } \\
\text { Facebook application }\end{array}$ \\
\hline Evaluation & $\begin{array}{l}\text { Iterate back to the design of } \\
\text { the artefact }\end{array}$ & $\begin{array}{l}\text { Identification of areas to improve the Calorie } \\
\text { Cruncher application }\end{array}$ \\
\hline Communication & $\begin{array}{l}\text { Publish and communicate the } \\
\text { results }\end{array}$ & $\begin{array}{l}\text { Conference publication to communicate and } \\
\text { discuss the results in order to develop this } \\
\text { project further }\end{array}$ \\
\hline
\end{tabular}

Table 1. Design science research methodology (DSRM) adopted from (Peffers et al., 2007)

\subsection{Problem Identification and Motivation}

The motivation of this study is to address an important gap in literature, that is, to measure the influence of different online relationships on the individual's body weight (Moore, 2010). As a first step, this study requires a large dataset containing personal online social network data, as well as information on an individual's health-related behaviours. Thus, we chose to use data from the most popular social network site Facebook by designing a Health 2.0 Facebook application to collect the required data that would lead to higher data reliability and a more efficient data collection process than the use of self-reported survey data (McCarty, 2002; Vitak, Ellison, \& Steinfield, 2011).

\subsection{Definition of Objectives for the Application}

We designed the application according to the steps of the DSRM. The solution used for the data collection needs to fulfil the following objectives:

1. Provide access to user profiles on Facebook

2. Provide access to the users' network of friends (full personal networks)

3. Provide access to the users' interaction with their Facebook friends

4. Gather data on the users' health status and health-related behaviours

An application in the area of fitness and sports should facilitate the collection of longitudinal data to facilitate a better understanding of people's behaviour over the course of time and thus enable the detection of causal inferences.

\subsection{Application Design and Development}

The design and development requirements are through qualitative interviews to determine the artefact's desired functionality and its architecture. By exploring the influence of people's offline social networks on their health-related behaviours and body weight, the findings of the interviews will inform the design and the development of the application's features. Translating the influencing social factors into application features also supports the 
continuous engagement with the application on the long run and enables us to collect longitudinal data.

\subsection{Design Sampling}

Using a purposeful sampling (Flick, 2009), the interviewees were selected based on currently experiencing problems with overweight and obesity or having experienced weight issues in the past (Table 2).

\begin{tabular}{|c|c|c|c|c|c|}
\hline Interviewee & Age & Sex & Occupation & $\begin{array}{c}\text { Marital } \\
\text { status }\end{array}$ & $\begin{array}{l}\text { Weight } \\
\text { status* }\end{array}$ \\
\hline 1 & 29 & $\mathrm{~F}$ & Student, journalist & Single & Obese \\
\hline 2 & 26 & $\mathrm{~F}$ & Dental assistant & Single & Overweight \\
\hline 3 & 28 & $\mathrm{~F}$ & Dental assistant & Engaged & Overweight \\
\hline 4 & 26 & $\mathrm{~F}$ & Works in the public sector & $\begin{array}{l}\text { In a } \\
\text { relationship }\end{array}$ & Normal \\
\hline 5 & 26 & $\mathrm{~F}$ & $\begin{array}{l}\text { Sales assistant, works free- } \\
\text { lance as an educationalist }\end{array}$ & Single & Overweight \\
\hline 6 & 21 & $\mathrm{~F}$ & $\begin{array}{l}\text { Management assistant in office } \\
\text { communication }\end{array}$ & Single & Obese \\
\hline 7 & 22 & $\mathrm{~F}$ & Student, waitress & Single & Normal \\
\hline 8 & 24 & M & Hairdresser & Single & Normal \\
\hline 9 & 24 & $\mathrm{M}$ & Media designer & Single & Overweight \\
\hline 10 & 39 & $\mathrm{M}$ & Real estate agent & Married & Obese \\
\hline 11 & 23 & M & IT Technician & Single & Normal \\
\hline 12 & 24 & M & Student & Single & Overweight \\
\hline 13 & 39 & $\mathrm{M}$ & Senior Manager & Married & Obese \\
\hline 14 & 35 & M & Senior Manager & Single & Overweight \\
\hline
\end{tabular}

\section{Table 2. Overview of the interviewees}

All selected interviewees were required to either currently engage in activities to lose weight or to have substantially reduced their body weight in the past. We included people from different stages of the weight loss process, since the study participants needed to be aware of their weight issues, and be able to reflect on the influence of their real-world social networks in different stages of the previous weight gain and current weight loss process. Being a member of Facebook was a third requirement.

\subsection{Design Data Collection}

The interview guideline included six sections addressing different areas of the process of weight gain and weight loss. Dealing with the very delicate and personal topic of obesity, data was collected through semi-structured open ended interviews (Hopf, 2007). As such, the interviews left room for spontaneous questions and allowed for in-depth exploration of the relationship between the interviewees' personal traits, social environment and their healthrelated behaviours. Direct interaction made it possible to control the flow, to avoid misunderstandings, to shift the interview's focus to particularly interesting aspects or to 
neglect certain areas of interrogation if the interviewee did not seem comfortable. Open-ended questions were advantageous as the interviewees had to provide answers based on their personal experiences (Flick, 2009).

\subsection{Design Data Analysis}

The data coding was conducted using NVivo, with inductive category building of free nodes categorizing the environment, reasons for weight gain and motivation to lose weight (Mayring, 2000). Following this process resulted in 154 free nodes. An example for a free node coding in "comparison with others" is "My friends do sports, too, and that motivates me to engage in physical activity as well (...)" [Interviewee 9]. Subsequently, the free nodes were classified into categories and organised into tree nodes. Table 3 shows a sample of tree node coding. Redundancies were checked for and eliminated, resulting in a final number of 131 nodes. The analysis of interview data followed approaches recommended by Boyatzis (1998), Kvale (1996) and Yin (2009).

\begin{tabular}{|l|l|c|}
\hline \multicolumn{2}{|l|}{ Tree nodes } & References \\
\hline \multirow{4}{*}{ Social pressure } & Slim friends & 8 \\
\cline { 2 - 3 } & Bad conscience & 1 \\
\cline { 2 - 3 } & Comparison with others & 21 \\
\cline { 2 - 3 } & Competition with others & 4 \\
\cline { 2 - 3 } & Common weight loss & 8 \\
\cline { 2 - 3 } & Sports together & 5 \\
\hline
\end{tabular}

Table 3. Example tree node coding

\subsection{Design Results}

Based on reports on offline social networks, online social networks may influence healthrelated behaviours in several ways. Firstly, social networks are suggested to influence people's norms and value system that have an impact on their health-related behaviours. The family social environment was mentioned as an important determinant of norms in terms of eating behaviours [Interviewee 10].

Secondly, social control and pressure of social connections may also shape health-related behaviours, and operate implicitly when people make food selection decisions [Interviewee 7]. "In the gym, I met many sportive and body-conscious people who have now become my friends. Even if I don't aim for a six pack, which some of my friends have, it does motivate me."

Thirdly, social relationships may provide emotional support (Rostila, 2011) for individual health-related behaviours, and interviewees' success and progress in the weight loss process made them feel more attractive, admired and socially accepted. However, a negative influence on people's emotional state is best illustrated by the fact that people engage in eating as a redirection activity due to experiencing emotional distress [Interviewee 7]. Further, a feeling of loneliness resulting from a lack of friends was mentioned as a reason for less physical activity on the one hand [Interviewee 9] and comfort in eating on the other hand [Interviewee 2]. Considering these findings, an award system as well as features enabling the comparison with other users were incorporated in the Facebook application.

\subsection{Design Implications}

To facilitate a better understanding of the relationship between people's social networks and their health-related behaviours, the three factors (1) value system, (2) social pressure and control and (3) emotional support were included as intervening variables in the presented model (Figure 3). Table 4 provides an overview of the main findings of the qualitative 
interviews according to the three factors with the derived design implication for the Facebook application.

\begin{tabular}{|c|c|c|}
\hline Intervening factors & Summary of findings & Design implications \\
\hline Value system & $\begin{array}{l}\text { Social networks are an important } \\
\text { determinant of norms in terms of health- } \\
\text { related behaviours } \\
\text { - Social networks are a source of } \\
\text { informational support } \\
\text { - Enabling the comparison with others, } \\
\text { social networks influence an individual's } \\
\text { norms and values }\end{array}$ & 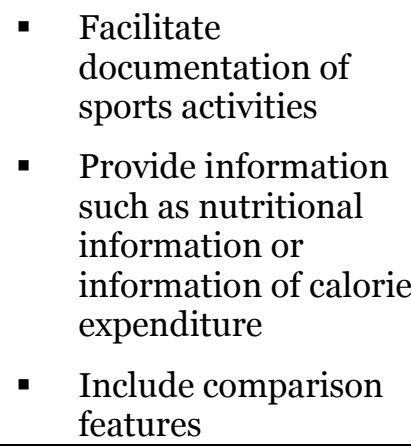 \\
\hline $\begin{array}{l}\text { Social pressure and } \\
\text { control }\end{array}$ & $\begin{array}{l}\text { - Social networks influence health-related } \\
\text { behaviours by providing role models } \\
\text { - Social networks exert social control and } \\
\text { create social pressure through competition } \\
\text { with others }\end{array}$ & $\begin{array}{l}\text { - Enable monitoring of } \\
\text { friends' sports } \\
\text { activities } \\
\text { - Include competition } \\
\text { features }\end{array}$ \\
\hline Emotional support & $\begin{array}{l}\text { - Social networks are a source of emotional } \\
\text { support (e.g. recognition) } \\
\text { - A lack of social contacts negatively effects } \\
\text { health-related behaviours }\end{array}$ & $\begin{array}{l}\text { - Provide a social } \\
\text { network "on the go" } \\
\text { - } \begin{array}{l}\text { Allow users to obtain } \\
\text { feedback from their } \\
\text { online social network }\end{array}\end{array}$ \\
\hline
\end{tabular}

Table 4. Summary of the interview findings and design implications

\subsection{Demonstration}

The beta version of the Calorie Cruncher application launched in October 2012 and counts 30 active users as of today.

\subsection{Data Collection}

The Calorie Cruncher successfully fulfilled the four main objectives by collecting online social network data, including (1) users' profile information, (2) users' network of friends and (3) users' interaction data, as well as (4) users' health data. 


\begin{tabular}{|c|c|c|c|}
\hline \multicolumn{3}{|c|}{ Online social network data } & \multirow[b]{2}{*}{ Health data } \\
\hline $\begin{array}{l}\text { Users' profile } \\
\text { information }\end{array}$ & $\begin{array}{l}\text { Users' network of } \\
\text { friends } \\
\end{array}$ & $\begin{array}{c}\text { Users' interaction } \\
\text { data }\end{array}$ & \\
\hline \multirow{8}{*}{$\begin{array}{ll}\text { - } & \text { User ID } \\
\text { - } & \text { Gender } \\
\text { - } & \text { Birthday } \\
\text { - } & \text { Work and education } \\
\text { history } \\
\text { - } \text { Hometown } \\
\text { - } \text { Current location } \\
\text { - } \begin{array}{l}\text { Activities and } \\
\text { interests }\end{array}\end{array}$} & \multirow{8}{*}{$\begin{array}{ll}\text { - } & \text { Friends' user IDs } \\
\text { - } & \text { Friendship status } \\
\text { between the user's } \\
\text { friends }\end{array}$} & - $\quad$ Status updates & \multirow{8}{*}{$\begin{array}{ll}\text { - } & \text { Body height } \\
\text { - } & \text { Body weight } \\
\text { - } & \text { Activity level } \\
\text { - } & \begin{array}{l}\text { Health-related } \\
\text { behaviour }\end{array}\end{array}$} \\
\hline & & - Wall posts & \\
\hline & & - Check-ins & \\
\hline & & - $\quad$ Picture IDs & \\
\hline & & likes on the & \\
\hline & & $\begin{array}{l}\text { previously } \\
\text { mentioned }\end{array}$ & \\
\hline & & interactions & \\
\hline & & - $\quad$ Picture tags & \\
\hline
\end{tabular}

Table 5. Data collected via the Calorie Cruncher application

All Facebook IDs are made anonymous to protect the privacy of the participants. With regard to the users' profiles, we collected information on gender, age, work and education history, hometown, their current location and their activities and interests - depending on the completeness of the Facebook profile information. The access to data from friends' networks enabled us to identify full personal networks, which facilitate the calculation of network-based measures like density or the identification of cliques within an individual Facebook network. For users' interaction data, the solution collects information on status updates, wall posts, check-ins and picture IDs and the respective Facebook Likes and comments on those interactions. Additionally, we have access to picture tags to identify if one or more Facebook users are in the same picture. With respect to the health data, Calorie Cruncher gathered data on the user's health status, tracks activities and monitors the body weight over time.

\subsection{Implementation of Design Implications}

Calorie Cruncher was developed according to findings from the qualitative study. Users of this application can "crunch" (burn) calories or take in calories, as well as share these activities with their friends. Additionally, we implemented the design implications based on the identified intervening factors (see Figure 2), to ensure frequent use and spread of the application on Facebook in order to monitor health data and online social network data over time.

Calorie Cruncher works like a diary that documents all activities (value system [1]). By providing statistics on the user's activities and BMI measures, the application enables the monitoring of the user's activities over time and, provides statistics on the activities of friends (value system [2]). On the landing page (screen 1) of the Calorie Cruncher, the application shows a health radar to indicate the current health status of the user (value system [3]). 


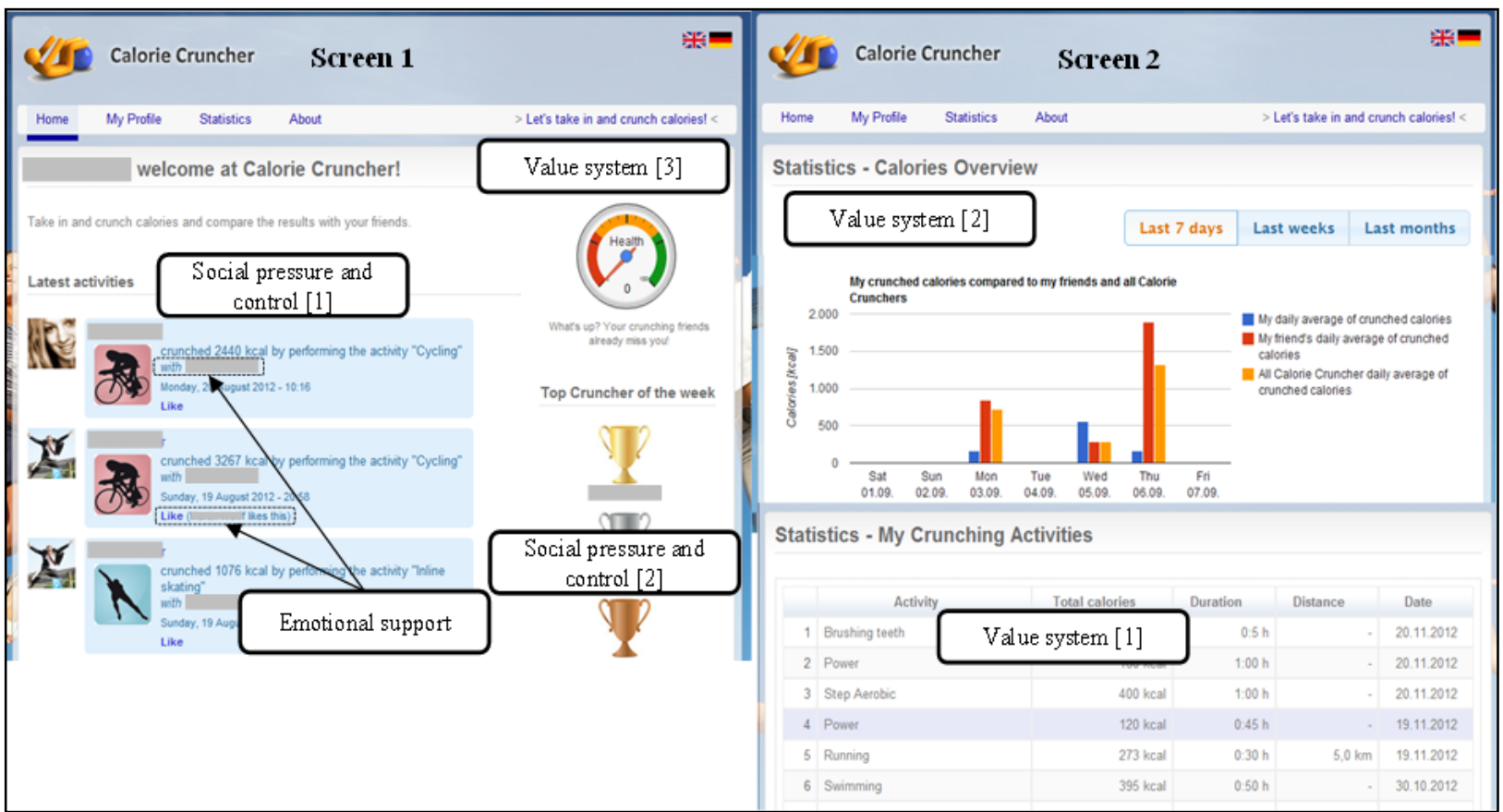

Figure 2. Screenshots of the Calorie Cruncher application

With regard to emotional support, we included features fostering the socialising aspect (Yee, 2006) to provide users with a sports club network "on the go". Users can document activities performed with other Facebook friends, who do not need to be users of Calorie Cruncher. Moreover, every Calorie Cruncher user can like - and in this manner support - the activities a user performed (emotional support). All activities can be shared on the Facebook wall, to allow user's Facebook friends to like and comment on those activities. Hence, a connection between Calorie Cruncher activities and the Facebook wall can be established and other Facebook members may be encouraged to start using the application.

\subsection{Evaluation}

The Facebook application Calorie Cruncher successfully collected all the required online social network data and the users' health data. The challenge lies in the cleaning, preparation, aggregation and management of the data in order to use them for further analysis, and in the identification of meaningful relations. Most users only communicate with a very small and distinct number of people out of their total number of online friends (Byron, Lento, Marlow, \& Rosenn, 2009), and these friends are expected to exert a higher influence on the individual, and they are identified by the frequency of interaction (Ellison, Steinfield, \& Lampe, 2007). In this case interaction measures have to be developed based on the raw data set.

With regard to the design of the Calorie Cruncher application, we are still in the pilot stage, since as of today we only have 30 active users. More promotion is planned in order to boost the user base. The application testing was successful, but we still need to conduct user acceptance testing.

\section{Discussion and Conclusion}

Finding innovative, effective and efficient ways to enable health and wellness to ensue is indeed a global priority and a huge societal challenge today. The preceding has served to outline a role for an innovative use of technology in addressing the current complex and pressing issue of the obesity epidemic. Specific contributions to theory and practice are identified below.

\subsection{Theoretical Implications}

This study has successfully refined our conceptual model (Figure 3) based on the findings of the qualitative interviews. 


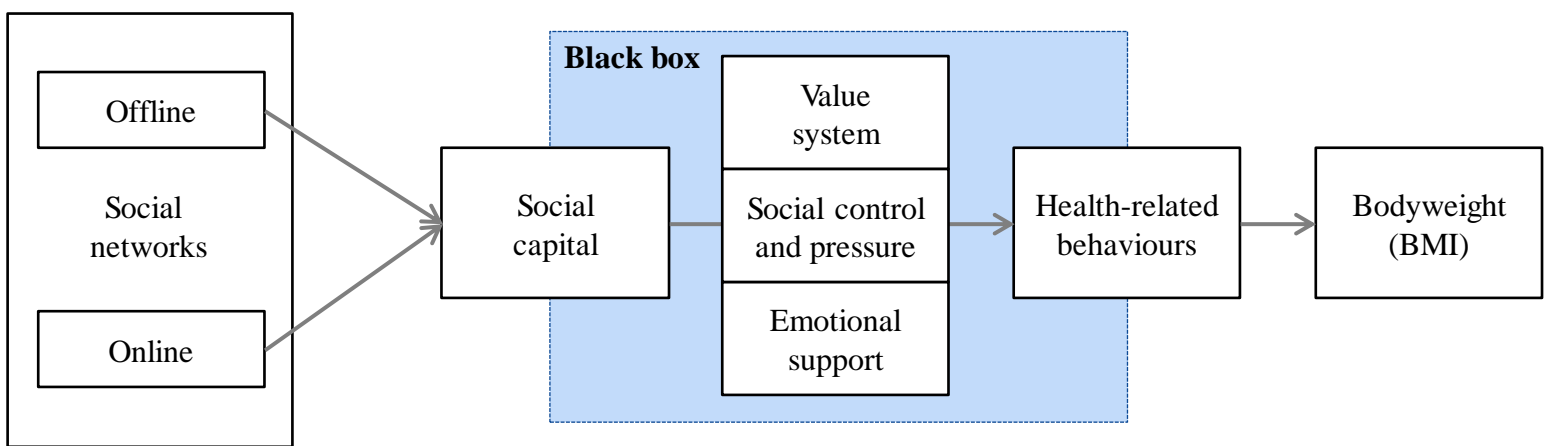

Figure 3. Revised relationship between social networks, health-related behaviours and health

We have inductively identified three factors that influence specific types of health outcomes in the context of obesity (Moore, 2010): (1) value system, (2) social pressure and control and (3) emotional support. By carefully examining the extant literature and then designing and developing a technology solution together with user input that focuses on empowering and supporting individuals, our study contributes to existing literature. Building on the aboveidentified three factors has enabled this study to enter into the black box, that is, to shed light on the relationship between online social networks and health-related behaviours (Figure 3). In particular, the extended conceptual model has the potential to establish causality between online social networks and good health, which has been found difficult to achieve to date (Hyyppä, 2010; Kim et al., 2008; Moore, 2010).

It is important to note that healthcare delivery is changing (Wickramasinghe \& Schaffer, 2010), and is influenced by rising healthcare costs, advances in technology, growth in chronic disease such as diabetes and obesity, and patient expectations and desires to be more empowered (Eysenbach, 2000; Wickramasinghe \& Schaffer, 2010). Eysenbach shows that individuals are desirous to be more empowered and supported in their own health and well-being maintenance (Figure 4) (Eysenbach, 2000). In particular, he asserts that this has contributed significantly to the rise of the emerging and nascent domain of consumer health informatics (ibid). Hence, what we have is an evolution in the practice of medicine with an emphasis on prevention and self-help which necessitates an engaged, empowered and informed patient. This can only be realised if ICT solutions are innovative or applied in an innovative fashion (as is the case with Calorie Cruncher). Calorie Cruncher facilitates the collection of user profile data, interaction data, and health-related data. As such, it enables the application of big data analytics in the context of obesity and online social networks, e.g. to analyse the relationship between a user's interaction patterns, friendship network, and their health status. We contend therefore, that online social networks will have a growing and significant role to play in the delivery of effective, efficient high value healthcare in today's information age. Further, our study is perhaps one of the first to theoretically identify the underlying reasons for the importance of online social networks to support and facilitate superior healthcare delivery. 

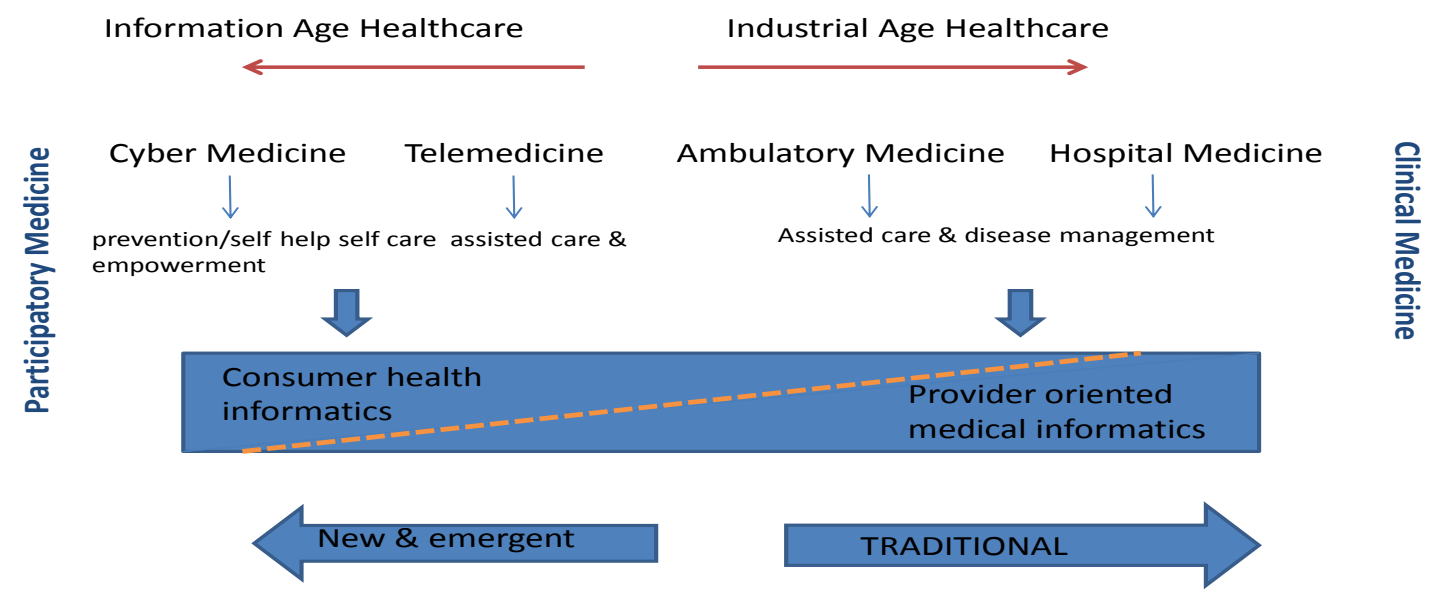

Figure 4. The changing face of healthcare delivery (adapted from: Eysenbach, 200o)

\subsection{Practical Implications}

Lessons learned from designing this Health 2.0 Facebook application would enable medical and healthcare practitioners to (1) understand the effect of obesity propagation in online social networks; (2) identify potential online intervention strategies to disseminate health-related information to the right group of people and (3) to offer services fostering positive healthrelated behaviours or to promote behaviour change advice. By exploring the social aspects of obesity and their effect in online social networks, this research will help to facilitate appropriate health-related behaviours using innovative consumer healthcare technologies, and will serve to inform the development of possible online intervention strategies. Further, for patients to be truly empowered to address key drivers impacting their chronic disease they need to understand and identify factors that influence and support healthy lifestyles. The proffered solution addresses this and thus supports heightened patient empowerment. In so doing, it also provides an example of how current technologies can support and facilitate the fostering of participatory medicine.

\subsection{Limitations and Future Research}

The application designed in this exploratory study is based on interview data gathered from a relatively small number of participants. However, after the pilot study and demonstration, we were able to collect sufficient data to enable deeper analysis.

To date, modern living and or more sedentary life style typically has been blamed for the rise in many chronic diseases such as obesity and diabetes. Kling noted that technology has both positive and negative impacts (Kling, 1996). To date however, as connected with chronic disease, we too often only hear the negative aspects or consequences of technology. We believe our research has served to underscore in a systematic fashion how technology might be able to assist in a significant, positive way to address a key global challenge and complex societal issue of addressing many chronic disease epidemics such as obesity and diabetes. Thus, the implications of this study are important, significant and far-reaching.

\section{Acknowledgements}

All appropriate ethics clearances have been received by the respective universities of the coauthors. A study of this type challenges aspects of privacy and the ability to withdraw as the Facebook technology used moves some of the control outside the researchers' immediate control. The respective ethics committees were satisfied that the nature of the study was fully explained and as individuals recruited were Facebook users they were familiar with Facebook. Further, identifiable data was only made available by the individuals themselves to those friends they chose to share the data; i.e. the researchers did not share any data to others except 
as aggregated de-identified data. Individuals were free to withdraw at any time. Their own Facebook accounts were their accounts to manage as they desired so this was never impacted or impeded by the study.

The authors acknowledge funding received from ATN - DAAD Joint Research Co-operation Scheme 1 January 2012 - 31 December 2013 which assisted them in conducting their research.

\section{References}

Arnaboldi, V., Passarella, A., Tesconi, M., \& Gazzè, D. (2011). Towards a Characterization of Egocentric Networks in Online Social Networks. In R. Meersman, T. Dillon, \& P. Herrero (Eds.), On the Move to Meaningful Internet Systems: OTM 2011 Workshops (pp. 524533). Crete: Springer Berlin Heidelberg. doi: 10.1007/978-3-642-25126-9_64

Bos, L., Carroll, D., \& Marsh , A. (2008). The impatient patient. Studies in health technology and informatics, 137, 1-13.

Bos, L., Marsh, A., Carroll, D., Gupta, S., \& Rees, M. (2008). Patient 2.o Empowerment. Paper presented at the SWWS.

Boyatzis, R. (1998). Thematic analysis and code development: Transforming qualitative information. London: Sage.

Boyd, d. m., \& Ellison, N. (2007). Social Network Sites: Definition, History, and Scholarship. Journal of Computer-Mediated Communication, 13, 210-230. doi: 10.1111/j.10836101.2007.00393.x

Brewer, J. \& Hunter, A. (1989). Multimethod Research. A synthesis of styles. Newbury Park: Sage.

Bruderl, J. \& Preisendorfer, P. (1998). Network support and the success of newly founded businesses. Small Business Economics, 19, 213-225.

BVDW. (2010). Social Media Kompass 2010/2011. Düsseldorf: Fachgruppe Social Media im Bundesverband Digitale Wirtschaft (BVDW) e.V.

Byron, L., Lento, T., Marlow, C., \& Rosenn, I. (2009). Maintained Relationships on Facebook. Available at: https://www.facebook.com/notes/facebook-data-science/maintainedrelationships-on-facebook/55257228858/ [Accessed 29 January 2017]

Christakis, N. A., \& Fowler, J. H. (2007). The spread of obesity in a large social network over 32 years. The New England journal of medicine, 357, 370-379. doi: 10.1056/NEJMsa066082

Cohen-Cole, E., \& Fletcher, J. M. (2008). Is obesity contagious? Social networks vs. environmental factors in the obesity epidemic. Journal of health economics, 27, 13821387. doi: 10.1016/j.jhealeco.2008.04.005

Durst, C., Hamper, A., \& Müller, T. (2013). In J. Kandampully (Ed.), Service Management in Health and Wellness. Kendall Hunt Publishing.

Durst, C., Viol, J., \& Wickramasinghe, N. (2013). Online social networks, social capital and health-related behaviours: A state-of-the-art analysis. Communications of the Association for Information Systems, 32, 134-158.

Ellison, N., Steinfield, C., \& Lampe, C. (2007). The Benefits of Facebook "Friends:" Social Capital and College Students' Use of Online Social Network Sites. Journal of ComputerMediated Communication, 12, 1143-1168. doi: 10.1111/j.1083-6101.2007.00367.x

Eysenbach, G. (2000). Recent advances: Consumer health informatics. BMJ: British Medical Journal, 320(7251), 1713.

Flick, U. (2009). An introduction to qualitative research (4th ed.). London: Sage. 
Fowler, J. H., \& Christakis, N. A. (2008). Estimating Peer Effects on Health in Social Networks: A Response to Cohen-Cole and Fletcher; Trogdon, Nonnemaker, Pais. Journal of health economics, 27, 1400. doi: 10.1016/j.jhealeco.2008.07.001.

Gershenson, C. (2011). Epidemiology and Social Networks. Cir Cir, 79(3), 99-200.

Granovetter, M. S. (1973). The strength of weak ties. The American Journal of Sociology, 78, 1360-1380. doi: 10.1037/aoo18761

Hammond, R. A. (2010). Social influence and obesity. Current opinion in endocrinology, diabetes, and obesity, 17, 467-471.

Hevner, A. R., March, S. T., Park, J., \& Ram, S. (2004). Design Science in Information Systems Research. MIS Quarterly, 28, 75-105. doi: 10.1.1.110.8133

Hopf, C. (2007). Qualitative Interviews - ein Überblick. In U. Flick, E. von Kardoff, \& I. Steinke (Eds.), Qualitative Forschung: Ein Handbuch (5th ed., pp. 349-360). Reinbek bei Hamburg: Rowohlt Taschenbuch Verlag.

Huffman, S. K. (2011). BMI changes in Russian adults: The role of lifestyles and spousal relationships. Agricultural and Applied Economics Association. Available at: http://econpapers.repec.org/RePEc:ags:aaea11:102653 [Accessed 29 January 2017]

Hwang, K. O., Ottenbacher, A. J., Green, A. P., Cannon-Diehl, M. R., Richardson, O., Bernstam, E. V., \& Thomas, E. J. (2010). Social support in an Internet weight loss community. International Journal of Medical Informatics, 79(1), 5-13.

Hyyppä, M. T. (2010). Healthy Ties. Media. doi: 10.1007/978-90-481-9606-7

Kaplan, A. M., \& Haenlein, M. (2010). Users of the world, unite! The challenges and opportunities of Social Media. Business Horizons, 53, 59-68.

Kim, D., Subramanian, S. V, \& Kawachi, I. (2008). Social Capital and Physical Health. In I. Kawachi, S. V Subramanian, \& D. Kim (Eds.), Social Capital and Health (pp. 139-190). Springer New York. doi: 10.1007/978-0-387-71311-3_8

Kling R. (1996). Computerization and Controversy: Value Conflicts and Social Choices. San Diego: Academic Press.

Kvale, S. (1996). InterViews: An Introduction to Qualitative Research Interviewing. Thousand Oaks: SAGE Publications.

Lejbkowicz, I., Caspi, O., \& Miller, A. (2012). Participatory medicine and patient empowerment towards personalized healthcare in multiple sclerosis. Expert review of neurotherapeutics, 12(3), 343-352.

Lin, N. (2001). Social Capital: A Theory of Social Structure and Action. Cambridge: Cambridge University Press.

Ma, X., Chen, G., \& Xiao, J. (2010). Analysis of An Online Health Social Network. IHI' 10.

Madan, A., Moturu, S. T., Lazer, D., \& Pentland, A. S. (2010). Social sensing. Wireless Health 2010 on - WH '10. New York, New York, USA: ACM Press.

Maloney-Krichmar, D., \& Preece, J. (2002). The meaning of an online health community in the lives of its members: Roles, relationships and group dynamics. Paper presented at the 2002 International Symposium on Technology and Society, 2002. (ISTAS'O2).

Marmot, M., \& Wilkinson, R. G. (Eds.) (2005). Social Determinants of Health (2nd ed.). Oxford University Press.

Mayring, P. (2000). Qualitative Inhaltsanalyse. Forum Qualitative Sozialforschung / Forum: Qualitative Social Research, 1.

McCarty, C. (2002). Measuring Structure in Personal Networks. Journal of Social Structure, 3. 
McNeill, L. H., Kreuter, M. W., \& Subramanian, S. V. (2006). Social environment and physical activity: a review of concepts and evidence. Social science \& medicine (1982), 63, 10111022. doi: 10.1016/j.socscimed.2006.03.012

Moore, S., Daniel, M., Gauvin, L., \& Dubé, L. (2009). Not all social capital is good capital. Health \& Place, 15(4), 1071-7. doi:10.1016/j.healthplace.2009.05.005

Moore, S. (2010). Social Networks, Social Capital and Obesity: A Literature Review. In L. Dubé, A. Bechara, A. Dagher, A. Drewnowski, J. Lebel, P. James, \& R. Y. Yada (Eds.), Obesity Prevention (pp. 673 - 685). San Diego: Academic Press.

Oinas-Kukkonen, H. (2010). Behavior change support systems: A research model and agenda Persuasive Technology (pp. 4-14). Berlin: Springer-Verlag.

Oinas-Kukkonen, H., \& Harjumaa, M. (2009). Persuasive systems design: Key issues, process model, and system features. Communications of the Association for Information Systems, 24(1), 28.

Oulasvirta, A., Rattenbury, T., Ma, L., \& Raita, E. (2012). Habits make smartphone use more pervasive. Personal and Ubiquitous Computing, 16(1), 105-114.

Peffers, K., Tuunanen, T., Rothenberger, M. a., \& Chatterjee, S. (2007). A Design Science Research Methodology for Information Systems Research. Journal of Management Information Systems, 24, 45-77. doi: 10.2753/MISo742-1222240302

Putnam, R. D., Leonardi, R., \& Nanetti, R. Y. (1994). Making democracy work: Civic traditions in modern Italy. New Jersey: Princeton University Press.

Quetelet, L. A. J. (1871). Anthropométrie ou mesure des différentes facultés de l'homme. Bruxelles.

Rostila, M. (2011). A resource-based theory of social capital for health research: Can it help us bridge the individual and collective facets of the concept? Social Theory \& Health, 1-21. doi: $10.1057 /$ sth.2011.4

Rostila, M. (2011). The Facets of Social Capital. Journal for the Theory of Social Behaviour, 41(3), 308-326. doi:10.1111/j.1468-5914.2010.00454.x

Vitak, J., Ellison, N., \& Steinfield, C. (2011). The Ties That Bond: Re-Examining the Relationship between Facebook Use and Bonding Social Capital. Proceedings of the 44th Hawaii International Conference on System Sciences.

Wasserman, S., \& Faust, K. (1994). Social network analysis: methods and applications. Cambridge: Cambridge University Press.

WHO. (2000). Obesity: preventing and managing the global epidemic. Report of a WHO Consultation. WHO Technical Report Series 894, Geneva.

WHO. (2011a). BMI classification. Available at: http://apps.who.int/bmi/index.jsp?introPage=intro_3.html [Accessed 29 January 2017]

WHO. (2011b). Obesity and overweight. Available at: http://www.who.int/mediacentre/factsheets/fs311/en/index.html [Accessed 29 January 2017]

Wickramasinghe, N., \& Schaffer, J. (2010). Realizing value driven e-health solutions. Report for IBM. Washington DC.

Wickramasinghe N., Bali R., Goldberg S., \& Troshani I. (2012). Pervasive health knowledge management. New York.

Wickramasinghe, N., Teoh, S. Y., Durst, C., \& Viol, J. (2013). Insights From An Investigation Of The Design Of A Consumer Health 2.0 Application To Address The Relationship 
Between On-Line Social Networks And Health-Related Behaviours. In Proceedings of the 24th Australasian Conference on Information Systems. Melbourne.

Yee, N. (2006). Motivations for play in online games. CyberPsychology \& Behavior, 9, 772775. doi: 10.1089/cpb.2006.9.772

Yin, R. K. (2009). Case study research: Design and methods (Vol. 5). Thousand Oaks: Sage.

Copyright: (C) 2017 Hacker, Wickramasinghe \& Durst. This is an open-access article distributed under the terms of the Creative Commons Attribution-NonCommercial 3.0 Australia License, which permits non-commercial use, distribution, and reproduction in any medium, provided the original author and AJIS are credited.

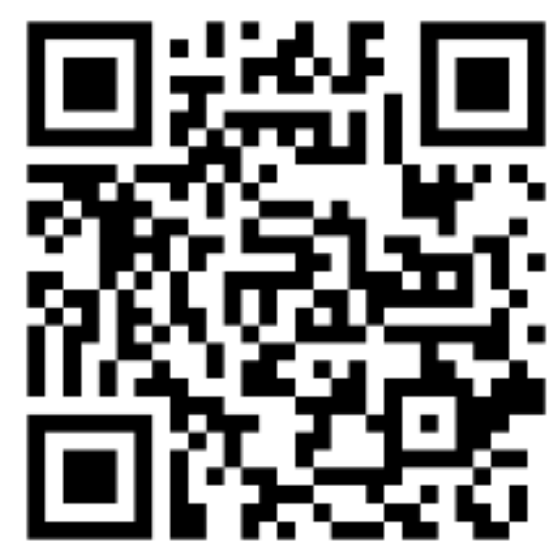

